\title{
Mineralização do carbono presente na casca de arroz através do processo de compostagem
}

A compostagem é um importante processo utilizado para estabilizar resíduos orgânicos e dar a estes a possibilidade de servir como fonte de nutrientes para as plantas. Assim, o objetivo do trabalho foi avaliar a eficiência da compostagem em promover a mineralização da casca de arroz e fezes de ovinos, alterando as propriedades químicas e físicas destes dejetos. Avaliando a relação $\mathrm{C} / \mathrm{N}$ após 80 dias, o processo de compostagem foi eficiente.

Palavras-chave: Composto; Dejetos; Húmus; Orgânico.

\section{Carbon mineralization in rice husks through composting process}

Composting is an important process used to stabilize organic waste and give these the possibility of serving as a source of nutrients for the plants. The study aim was to evaluate the composting efficiency in promoting mineralization of rice husks and sheep faeces, changing the chemical and physical properties of waste. Evaluating the $\mathrm{C} / \mathrm{N}$ ratio after 80 days, the composting process was effective.

Keywords: Composite; Humus; Manure; Organic.

Topic: Notas Científicas

Reviewed anonymously in the process of blind peer
Received: 12/01/2018

Approved: 24/04/2018
Lucas Jackson Souza (iD

Universidade Federal de Pelotas, Brasil

http://lattes.cnpq.br/3290908824115059

http://orcid.org/0000-0003-0765-1458

lucasjacksondesouza@hotmail.com

Rodrigo Chaves Barcellos Grazziotin (iD

Universidade Federal de Pelotas, Brasil

http://lattes.cnpq.br/7138349343512957

http://orcid.org/0000-0003-1966-9217

rodrigo.chavesbarcellosgrazziotin@sdstate.edu

Andressa Stein Maffi

Universidade Federal de Pelotas, Brasil

http://lattes.cnpq.br/2074660071238666

http://orcid.org/0000-0003-2242-9679

andressamaffi@gmail.com
Mauricio Cardozo Machado

Universidade Federal de Pelotas, Brasil

http://lattes.cnpq.br/3669768421846239

http://orcid.org/0000-0003-2478-5036

zoo2012.2mauricio@gmail.com

Cassio Cassal Brauner (iD)

Universidade Federal de Pelotas, Brasil

http://lattes.cnpq.br/5518025291169624

http://orcid.org/0000-0001-5248-2476

cassiocb@gmail.com

Fernanda Medeiros Gonçalves

Universidade Federal de Pelotas, Brasil

http://lattes.cnpq.br/3890154245380734

http://orcid.org/0000-0002-0032-3059

fmedeiros fv@ufpel.edu.br
Referencing this:

SOUZA, L. J.; GRAZZIOTIN, R. C. B.; MAFFI, A. S.; MACHADO, M. C.; BRAUNER, C. C.; GONÇALVES, F. M.. Mineralização do carbono presente na casca de arroz através do processo de compostagem. Natural Resources, v.8, n.1, p.70-74, 2018. DOI: http://doi.org/10.6008/CBPC2237-9290.2018.001.0008 


\section{INTRODUÇÃO}

A agricultura e a pecuária movimentam grandes quantidades de resíduos, como dejetos de animais e restos de culturas, palhas e resíduos agroindustriais e quando não descartados de forma correta, podem trazer prejuízos além de problemas ambientais. A região Sul, do Rio Grande do Sul (RS), possui expressiva representação na produção de arroz, gerando uma grande quantidade de resíduos. Estima-se que para cada tonelada de arroz, são gerados $230 \mathrm{~kg}$ de casca. Esse resíduo é composto por $50 \%$ de celulose, $30 \%$ de lignina e $20 \%$ de sílica (MEHTA et al., 1977), e atualmente tem sido explorado como biomassa para a geração de energia devido ao seu alto potencial carbonífero (MAYER et al., 2007). Além disso, a casca de arroz é comumente utilizada na composição de camas para animais em confinamento, tais como aves, suínos, bovinos e ovinos.

Porém, a preocupação encontra-se na forma de destinação desta cama, considerando que a mesma apresentará um alto teor de matéria orgânica devido à incorporação dos dejetos provenientes dos animais. Como uma importante alternativa, tem-se o uso de compostagens, pois além de amenizar os problemas da degradação do solo, incorpora matéria orgânica a este, e oferece um destino nobre a dejetos antes mal aproveitados (HAMMES, 2002). A compostagem modifica as características químicas e físicas dos dejetos, dando origem a um produto final com alto valor agronômico (GIACOMINI et al., 2014).

Pode-se definir compostagem como um processo controlado de decomposição microbiana, oxidação e oxigenação de uma massa heterogênea de matéria orgânica no estado sólido e úmido, passando pelas seguintes fases: uma inicial e rápida de fitotoxicidade ou de composto cru, seguida da fase de semicura ou bioestabilização, para atingir finalmente a terceira fase, a cura, ou mais tecnicamente, a humificação (KIEHL, 2004). Esta última é acompanhada da mineralização de determinados componentes da matéria orgânica tornando-os biodisponíveis as plantas.

Este processo é afetado pela umidade, níveis de oxigênio, temperatura, $\mathrm{pH}$, granulometria e pela relação carbono/nitrogênio (C/N) (MASSUKADO, 2008). Com isso, a hipótese do presente estudo é que a compostagem promove a mineralização da cama de ovinos confinados. Nesse sentido o objetivo foi avaliar a eficiência da compostagem em promover a mineralização da cama de ovinos confinados, alterando as propriedades químicas e físicas desses dejetos.

\section{METODOLOGIA}

O material de estudo foi obtido no pavilhão de ovinos, pertencente ao Hospital de Clínicas Veterinária de Grandes Animais, localizado no Campus Universitário da Universidade Federal de Pelotas (UFPel), no município do Capão do Leão, sendo que a coleta das amostras ocorreu no outono de 2015. Neste pavilhão ficavam alocados 39 ovinos, distribuídos em oito baias, e semanalmente realizava-se a retirada da cama das baias contendo casca de arroz e fezes de ovinos. $O$ descarte desses dejetos era realizado em uma área externa ao pavilhão, na forma de camadas, a céu aberto, então, com a finalidade de verificar a ocorrência do processo 
de compostagem nos resíduos descartados de acordo com a forma descrita acima, foi realizada a coleta de amostras comportadas durante 05 (A1), 40 (A2) e 80 (A3) dias.

O material coletado foi enviado ao Laboratório de Nutrição Animal (LNA) da UFPel para quantificação do carbono, utilizando a fórmula C=M.O/1,8, sendo a matéria orgânica (M.O) obtida pela perda de massa do resíduo incinerado, levando em conta o material perdido pela queima no intervalo de variação da temperatura. O nitrogênio foi mensurado através do método de Kjeldahl (NOGUEIRA et al., 2005). Os dados foram analisados no programa estatístico livre ASSISTAT e submetidos à análise de variância e as médias foram comparadas pelo teste de Tukey a 5 \% de significância. Os resultados provenientes das três amostras coletadas (A1, A2, A3) estão descritos na Tabela 1.

\section{RELATO}

Na tabela 1 são apresentados os parâmetros físicos e químicos das amostras de cama de ovinos coletadas em diferentes momentos. Conforme observado na Tabela 1, os níveis de carbono aumentaram no decorrer do período avaliado. Os resultados divergem aos encontrados por Gorgati (2001) e Kiehl (2004) onde observaram uma relação inversa desses parâmetros.

Tabela 1: Descrição dos parâmetros avaliados nas amostras A1, A2 e A3 de compostagem de palha de arroz e fezes de ovinos, realizados em uma composteira a céu aberto.

\begin{tabular}{lllll}
\hline Parâmetro, \% & A1 (5 dias) & A2 (40 dias) & A3 (80 dias) & Valor de P \\
\hline MS & $93,99^{a}$ & $94,13^{\mathrm{a}}$ & $93,68^{\mathrm{b}}$ & 0,003 \\
Cinzas & $74,4^{\mathrm{a}}$ & $61,56^{\mathrm{b}}$ & $37,03^{\mathrm{c}}$ & $<0,0001$ \\
MOrg & $19,59^{\mathrm{c}}$ & $32,57^{\mathrm{b}}$ & $56,65^{\mathrm{a}}$ & $<0,0001$ \\
Carbono orgânico & $10,87^{\mathrm{c}}$ & $18,09^{\mathrm{b}}$ & $31,47^{\mathrm{a}}$ & $<0,0001$ \\
Nitrogênio & 1,09 & 0,98 & 1,23 & 0,063 \\
Relação C/N & $10 / 1^{\mathrm{c}}$ & $18 / 1^{\mathrm{b}}$ & $26 / 1^{\mathrm{a}}$ & 0,0031 \\
\hline
\end{tabular}

$\mathrm{MS}=$ matéria seca; $\mathrm{MOrg}$ = matéria orgânica; Relação $\mathrm{C} / \mathrm{N}=$ relação carbono/nitrogênio.

O método utilizado no presente estudo para obtenção dos níveis de carbono das amostras, considera apenas o carbono orgânico. Contudo, a casca de arroz possui uma média de $42 \%$ de carbono inorgânico quando comburido (CHUNGSANGUNSIT et al., 2004) o qual fica retido no teor de cinzas, justificando o baixo conteúdo de carbono orgânico na amostra inicial (A1). Devido a essa característica, durante o processo de combustão a cinza de casca de arroz na fase imatura, irá conter uma quantidade elevada de carbonato não queimado (ZEMKE et al., 2009). Tal afirmação pode ser sustentada pelos níveis de cinzas e matéria orgânica observados, apresentando uma relação inversamente proporcional nas cinzas, ou seja, conforme aumenta o tempo de compostagem, diminui o teor deste parâmetro, sendo diretamente proporcional para matéria orgânica.

Após os diferentes períodos de compostagem (A1 e A2), o carbono fixo antes indisponível na casca não curada, foi metabolizado pelos microrganismos, passando a constituir a matéria orgânica. A partir desses resultados, observou-se que o processo de compostagem do presente estudo foi eficiente para transformação deste elemento para forma orgânica, justificado pelo aumento no Carbono orgânico e redução nos níveis de cinzas. 
A concentração de nitrogênio se manteve estável ao longo do processo, esse elemento químico é fundamental para o crescimento e reprodução dos microrganismos, então, mesmo que exigido em quantidades menores do que o carbono, a insuficiência de nitrogênio é um fator limitante no processo de compostagem (VALENTE et al., 2009). Conforme citado por alguns pesquisadores, a relação $\mathrm{C} / \mathrm{N}$ ideal para a formação da composteira está entre 25 e 35/1 (FONG et al., 1999; KIEHL, 2004). Porém, quando estável no composto, deve estar presente uma relação entre 10/1 e 20/1, conforme a Instrução Normativa SDA no 25 (MAPA, 2009).

Nesse estudo, esse parâmetro teve uma relação inferior (A1), tendo o incremento com o passar do tempo (A2 e A3). Isso pode ser justificado ao carbono fixo no início do processo, como debatido acima. Resultados semelhantes foram encontrados por Silva et al. (2009) quando utilizaram serragem ou pedaços de madeira associados ao esterco de aves para o processo de compostagem. A maturação dos dejetos ainda não estava adequada para utilização (A3), sendo necessário um período maior para o processo, o que não estaria fora dos padrões, pois o período total de compostagem é estimado entre 100 a 120 dias (SOUZA et al., 2006). Apesar de não seguir os padrões estipulados, o processo de compostagem ocorreu de forma correta quando avaliada a relação $\mathrm{C} / \mathrm{N}$.

\section{CONCLUSÕES}

A partir dos resultados apresentados, pode-se concluir que o processo de compostagem é uma alternativa sustentável para o descarte da cama de ovinos, pois promove a mineralização desse material, porém esse processo apresenta características físicas e químicas ao longo do processo, distintas das apresentadas por outros materiais utilizados na compostagem, com isso, sugere-se novos estudos a fim de determinar o melhor método de compostagem deste material.

\section{REFERÊNCIAS}

CHUNGSANGUNSIT, T.; GHEEWALA, S. H.; PATUMSAWAD, S. Environmental Profile of Power Generation from Rice Husk in Thailand. In: THE JOINT INTERNATIONAL CONFERENCE ON 'SUSTAINABLE ENERGY AND ENVIRONMENT (SEE)'. Anais. Hua Hin: Thailand, 2004

FONG, M.; WONG, J. W. C.; WONG, M. H.. Review on evaluation of compost maturity and stability of solid waste. Shanghai Environmental Sciences, Pequim, v.18, p.91-93, 1999.

GIACOMINI, D. A.; AITA, C.; PUJOL, S. B.; GIACOMINI, S. J.; DONEDA, A.; CANTÚ, R. R.; DESSBESEL, A.; LÜDTKE, R. C.; SILVEIRA, C. A. P.. Mitigação das emissões de amônia por zeólitas naturais durante a compostagem de dejetos de suínos. Pesquisa Agropecuária Brasileira, Brasília, v.49, n. 7, p.521-530, 2014. DOI: http://10.1590/S0100204X2014000700004

GORGATI, C. Q.. Resíduos sólidos urbanos em áreas de proteção aos mananciais - município de São Lourenço da Serra - SP: compostagem e impacto ambiental. Tese (Doutorado em Agronomia) - Universidade Estadual Paulista "Júlio de Mesquita Filho", São Paulo, 2001.
HAMMES, V. S.. Educação Ambiental para o Desenvolvimento Sustentável. 5 ed. Brasília: Embrapa, 2002.

MAPA. Instrução Normativa $N^{\circ} 25$. Dispõe sobre especificações e as garantias, as tolerâncias, o registro, a embalagem e a rotulagem dos fertilizantes orgânicos simples, mistos, compostos, organominerais e biofertilizantes destinados à agricultura. Brasília: Ministério da Agricultura, Pecuária e Abastecimento, 2011.

KIEHL, E. J.. Manual de compostagem: maturação e qualidade do composto. 4 ed. Piracicaba: Livroceres, 2004.

MAYER, F. D; CASTELLANELLI, C.; HOFFMANN, R.. Geração de energia através da casca de arroz: uma análise ambiental. In: ENCONTRO NACIONAL DE ENGENHARIA DE PRODUÇÃO, 27. Anais. Foz do Iguaçu, 2007.

MASSUKADO, L. M.. Desenvolvimento do processo de compostagem em unidade descentralizada e proposta de software livre para o gerenciamento municipal dos resíduos sólidos domiciliares. Tese (Doutorado em 
Engenharia Ambiental) - Universidade de São Paulo, São Paulo, 2008.

MEHTA, P. K.; PITT, N.. A new process of rice utilization. In: INTERNATIONAL CONFERENCE ON THE UTILIZATION OF RICE BY-PRODUCTS. Anais. Valencia: IATA, 1977.

NOGUEIRA, A. R. A; SOUZA, G. B.. Manual de Laboratórios: Solo, Água, Nutrição Vegetal, Nutrição Animal e Alimentos. São Carlos: Embrapa Pecuária Sudeste, 2005.

SILVA, M. E.; LEMOS, L. T.; CUNHA-QUEDA, A. C.; NUNES, O. C.. Co-composting of poultry manure with low quantities of carbon-rich materials. Waste Management \& Research,
Padova, v.27, n.2, p.119-128, 2009. DOI: http://10.1177/0734242X08096693

SOUZA, J. L.; REZENDE, P. L.. Manual de Horticultura

Orgânica. 2 ed. Viçosa: Aprenda Fácil, 2006.

VALENTE, B. S.; XAVIER, E. G.; MORSELLI, T. B. G. A.; JAHNKE, D. S.; BRUM, B. S.; CABRERA, B. R.; MORAES, P. O.; LOPES, D. C. N.. Fatores que afetam o desenvolvimento da compostagem de resíduos orgânicos. Archivos de zootecnia. Argentina, v.58, n.1, p.59-85, 2009.

ZEMKE, N.; WOODS, E.. Rice husk ash. Tailândia: California Polytechnic State University, 2009.

A CBPC - Companhia Brasileira de Produção Científica (CNPJ: 11.221.422/0001-03) detém os direitos materiais desta publicação. Os direitos referem-se à publicação do trabalho em qualquer parte do mundo, incluindo os direitos às renovações, expansões e disseminações da contribuição, bem como outros direitos subsidiários. Todos os trabalhos publicados eletronicamente poderão posteriormente ser publicados em coletâneas impressas sob coordenação da Sustenere Publishing, da Companhia Brasileira de Produção Científica e seus parceiros autorizados. Os (as) autores (as) preservam os direitos autorais, mas não têm permissão para a publicação da contribuição em outro meio, impresso ou digital, em português ou em tradução. 